\title{
Simvastatin reduces sympathetic activity in men with hypertension and hypercholesterolemia
}

\author{
Jacek Lewandowski ${ }^{1}$, Maciej Siński ${ }^{1}$, Joanna Bidiuk ${ }^{1}$, Piotr Abramczyk ${ }^{1}$, Anna Dobosiewicz ${ }^{1}$, Agnieszka Ciarka ${ }^{2}$ \\ and Zbigniew Gaciong ${ }^{1}$
}

Beyond their hypolipidemic effect, statins reduce cardiovascular risk in hypertensive subjects via various mechanisms; one suggested mechanism is that they reduce sympathetic activity. We investigated the hypothesis that simvastatin decreased muscle sympathetic nerve activity (MSNA) in 31 hypertensive subjects with hypercholesterolemia (aged $38.7 \pm 10$ years). In this randomized, placebocontrolled, double-blinded study, patients were treated with simvastatin $\left(40 \mathrm{mg} \mathrm{day}^{-1} ; n=15\right)$ or placebo $(n=16)$ for 8 weeks. Before and after treatment, we measured MSNA, blood pressure and heart rate. Baroreceptor control of the heart rate, or baroreceptor sensitivity (BRS), was computed by the sequence method, a cross-analysis of systolic blood pressure and the electrocardiogram R-R interval. Blood samples were tested for plasma levels of catecholamines, neuropeptide $\mathbf{Y}$, aldosterone, endothelin and renin activity. Simvastatin significantly reduced MSNA (from $36.5 \pm 5$ to $27.8 \pm 6$ bursts per min, $P=0.001$ ), heart rate (from $77 \pm 6.7$ to $71 \pm 6.1$ beats per $\mathrm{min}, P=0.01$ ) and both total and low-density lipoprotein cholesterol (from $249 \pm 30.6$ to $184 \pm 28.3 \mathrm{mg} \mathrm{dl}^{-1}, P=0.001$ and from $169 \pm 30.6$ to $117 \pm 31.2 \mathrm{mg} \mathrm{dl}^{-1}, P=0.01$, respectively). Simvastatin also improved BRS (from $10.3 \pm 4.1$ to $17.1 \pm 4.3 \mathrm{~ms}$ per $\mathrm{mm} \mathrm{Hg}, P=0.04$ ). No changes were observed in systolic or diastolic blood pressures, or in plasma levels of catecholamines, neuropeptide $Y$, endothelin, aldosterone and renin activity. After simvastatin therapy, MSNA and BRS were inversely related $(r=-0.94, P<0.05)$. In conclusion, we found that, in patients with hypertension and hypercholesterolemia, simvastatin reduced MSNA, and this was related to increased baroreceptor sensitivity. Hypertension Research (2010) 33, 1038-1043; doi:10.1038/hr.2010.137; published online 29 July 2010

Keywords: hypercholesterolemia; microneurography; statins; sympathetic activity

\section{INTRODUCTION}

The influence of 3-hydroxy-3-methyl-glutaryl-CoA (HMG-CoA) reductase inhibitors, or 'statins', on plasma lipid concentrations is well established. ${ }^{1,2}$ Clinical effects of statins have been investigated in various groups of patients, particularly those with cardiovascular and metabolic disorders, in patients with low and high cardiovascular risks and in both primary and secondary preventions. ${ }^{3-8}$ Many randomized, placebo-controlled studies have shown that, in patients with hypercholesterolemia, a reduction in plasma cholesterol with HMG-CoA reductase inhibitors was followed by substantial reductions in cardiovascular morbidity and mortality. ${ }^{3-8}$ Furthermore, statins showed clinical efficacy in patients who did not have high cholesterol levels; this suggested that statins might exert beneficial effects in addition to their hypolipidemic actions. ${ }^{8-10}$

One cardioprotective mechanism of action may be related to statin's interactions with the neurohumoral system, particularly in the reninangiotensin pathway and the sympathetic nervous system. Statin's sympathoinhibitory effects have been tested in both animal and human models. In normolipidemic rabbits with heart failure, simvastatin increased heart rate variability (HRV) and reduced sympathetic outflow. ${ }^{11}$ In patients with hyperlipidemia, either with or without coronary artery disease, atorvastatin significantly improved the time and frequency domain indices of HRV; however, interestingly, post-therapeutic low-density lipoprotein (LDL) levels did not correlate with the indices of HRV. ${ }^{11}$ Furthermore, a few studies in patients with heart failure showed that statins improved sympathovagal balance, as reflected in the change in HRV indices. ${ }^{12,13}$ Statins are commonly prescribed for patients with hypertension, both with and without hypercholesterolemia, to reduce their cardiovascular risk. To date, no randomized, placebo-controlled studies have investigated whether statins can reduce sympathetic tone in subjects with hypertension, or ascertained the mechanisms involved.

The aim of this study was to conduct a randomized, placebocontrolled study on the influence of simvastatin on sympathetic activity in subjects with hypertension and hypercholesterolemia. Sympathetic activity was measured in vivo with microneurography.

\section{METHODS}

Subjects

We studied 31 men, aged $38.7 \pm 10$ years, with a mean body mass index of $28.0 \pm 4 \mathrm{~kg} \mathrm{~m}^{-2}$. The subjects had hypercholesterolemia, defined as fasting total

${ }^{1}$ Department of Internal Medicine, Hypertension and Vascular Diseases, Medical University of Warsaw, Warsaw, Poland and ${ }^{2}$ Department of Cardiology, Erasme Hospital, Brussels, Belgium

Correspondence: Dr J Lewandowski, Department of Internal Medicine, Hypertension and Vascular Diseases, Medical University of Warsaw, Banacha 1a, Warsaw 02-097, Poland. E-mail: j_lewandowski@yahoo.com

Received 5 March 2010; revised and accepted 19 May 2010; published online 29 July 2010 
Table 1 Characteristic of subjects in simvastatin and placebo group at baseline

\begin{tabular}{|c|c|c|c|}
\hline & Simvastatin & Placebo & $\mathrm{P}$-value \\
\hline Number of patients & 15 & 16 & NS \\
\hline Age (years) & $39.0 \pm 10.2$ & $38.3 \pm 10.1$ & NS \\
\hline $\mathrm{BMI}\left(\mathrm{kg} \mathrm{m}^{-2}\right)$ & $28.7 \pm 4.5$ & $27.3 \pm 4.1$ & NS \\
\hline $\begin{array}{l}\text { Blood pressure lowering medication, } \\
\text { number of patients (\% of total number) }\end{array}$ & $10(66.7 \%)$ & $11(68.75 \%)$ & NS \\
\hline $\mathrm{AT}_{1}$ receptor antagonists & $3(20.0 \%)$ & $3(18.7 \%)$ & NS \\
\hline ACE inhibitors & $4(26.6 \%)$ & $4(25.0 \%)$ & NS \\
\hline Calcium antagonists & $1(6.7 \%)$ & $1(6.25 \%)$ & NS \\
\hline$\beta$-Blockers & $2(13.3 \%)$ & $3(18.7 \%)$ & NS \\
\hline Diuretics & $1(6.7 \%)$ & $1(6.25 \%)$ & NS \\
\hline
\end{tabular}

Abbreviations: ACE, angiotensin-converting enzyme; BMI, body mass index; NS, nonsignificant.

and LDL cholesterol levels $\geqslant 190$ and $\geqslant 115 \mathrm{mg} \mathrm{dl}^{-1}$, respectively, and mild-tomoderate essential hypertension (blood pressures: 140-179/90-109 mm Hg). According to routine investigations and laboratory findings, other cardiovascular, metabolic, endocrine and neurological diseases were excluded. All subjects were screened to exclude central and peripheral neurological disorders. None of the subjects were currently using lipid-lowering drugs. Antihypertensive therapies, including angiotensin-converting enzyme inhibitor or $\beta$-adrenergic receptor inhibitor ( $\beta$-blocker), remained unchanged for 3 months before and during the study (Table 1). Patients were prohibited from the chronic use of drugs that might potentially influence the nervous system. Active smokers and alcohol abusers were excluded from the study. The day before the experiment, subjects were asked not to drink alcohol, coffee or use other stimulants. Informed consent was obtained from all participants. The institutional review board of the Medical University of Warsaw approved the study protocol.

\section{Study design}

The study was double blinded, randomized and placebo controlled. Subjects were assigned to $40 \mathrm{mg}$ of simvastatin (Simvasterol; Gedeon Richter Marketing Polska, Warsaw, Poland; $n=15)$ or placebo $(n=16)$. All recordings were performed twice: once before and once after 8 weeks of therapy. Recordings were performed in a calm investigation room after $30 \mathrm{~min}$ of supine rest. All subjects underwent recordings of muscle sympathetic nervous activity (MSNA), heart rate (HR) and continuous, non-invasive systolic and diastolic blood pressure (SBP and DBP, respectively). Blood samples were taken before each recording.

\section{Measurements}

HR was recorded continuously (Power Lab Data Acquisition System, AD Instruments, Colorado Springs, CO, USA). Blood pressure was measured with a digital photoplethysmograph device capable of providing accurate beat-tobeat systolic and diastolic values (Finapress, Ohmeda 2300, Monitoring Systems, Englewood, CO, USA). MSNA signals were obtained with the microneurography technique (Nerve traffic analysis system, University of Iowa, Iowa City, IA, USA). ${ }^{14}$ Briefly, a recording electrode was placed into the peroneal nerve at the popliteal fossa, posterior to the fibular head, and a reference electrode was placed subcutaneously $2-3 \mathrm{~cm}$ from the recording electrode. The nerve signals were amplified (gain 70000-160000), band-pass filtered $(700-2000 \mathrm{~Hz})$, full-wave rectified and integrated with a resistancecapacitance circuit (time constant $0.1 \mathrm{~s}$ ). The criteria for an adequate MSNA recording included: pulse synchrony; facilitation during the hypotensive phase of the Valsalva maneuver, and suppression during the hypertensive overshoot after release; and an increase in response to holding the breath. ${ }^{14}$

Baroreflex control of the HR, or baroreflex sensitivity (BRS), was measured with the non-invasive sequence method (Nevrokard ${ }^{\mathrm{TM}}$ BRS software, version 5.1.3, Nevrokard, Ljubljana, Slovenia). Input data for the software were generated with a Finapress monitor and the electrocardiogram. Briefly, the software identified sequences in which the electrocardiogram R-R intervals and the SBP and DBP concurrently increased or decreased for over three beats. The minimum change in blood pressure was set at $1 \mathrm{~mm} \mathrm{Hg}$ and the minimum change in the R-R interval was set at $5 \mathrm{~ms}$. The software used the combined results of the upward and downward sequences to calculate the BRS indices. The BRS was expressed in ms per mm Hg. This non-invasive method provided accurate assessments of BRS, comparable with those obtained with invasive methods. ${ }^{15}$

\section{Biochemical indices}

Plasma catecholamine concentrations were determined with high-pressure liquid chromatography and a commercial reagent kit (Chromsystems, Munich, Germany). Plasma neuropeptide Y (NPY) concentrations were estimated with the EURIA-NPY radioimmunoassay (Euro-Diagnostica, Malmo, Sweden). Measurement of endothelin was performed with a human endothelin-1 enzyme-linked immunosorbent assay kit (R\&D Systems, Minneapolis, MN, USA). Plasma aldosterone concentration and plasma renin activity were determined with the DSL 8600 radioimmunoassay (Diagnostic Systems Laboratories, Webster, MO, USA) and DSL 25100 radioimmunoassay (Immunotech, Praha, Czech Republic), respectively.

\section{Data analysis}

Sympathetic bursts were identified by careful inspection of voltage changes in neurograms in a blinded manner. Sympathetic activity was expressed as the number of bursts per minute (burst frequency) and the number of bursts per 100 heart beats (burst incidence).

\section{Statistical analysis}

Statistical analysis was performed with Statistica 8.0 software. Comparisons between baseline values in the treatment and placebo groups were performed with the unpaired Student's $t$-test. The responses to administration of simvastatin or placebo were analyzed with a repeated-measures analysis of variance, with time (before $v s$. after 8 weeks) as the 'within' factor and treatment (simvastatin vs. placebo) as the 'between' factor. Data are presented as mean \pm s.d. Statistical significance was established at $P<0.05$.

\section{RESULTS}

At baseline, the groups did not differ in sex, age, body mass index, SBP, DBP, HR or lipid concentrations (Tables 1 and 2). MSNA and BRS values were not significantly different in the control and treatment groups (Table 2).

\section{Effects of simvastatin on plasma lipids}

In comparison with baseline, simvastatin treatment reduced the plasma levels of total cholesterol, LDL cholesterol and triglycerides (Table 2), but did not change HDL cholesterol. In the placebo group, no changes were observed compared with baseline in total cholesterol, LDL cholesterol, HDL cholesterol or triglycerides (Table 2).

\section{Recorded variables before and after simvastatin therapy}

In comparison with baseline, simvastatin therapy reduced MSNA from $36.5 \pm 5$ to $27.8 \pm 6$ burst per min, $P=0.001$ (Figure 1) and HR from $77 \pm 6.7$ to $71 \pm 5.4$ beats per $\min , P=0.01$. When MSNA was normalized for a number of heart beats, the sympathetic activity decreased from $47.8 \pm 8$ to $39.4 \pm 8$ bursts per 100 heart beats, $P=0.001$. Simvastatin increased BRS from $10.3 \pm 4$ to $17.4 \pm 4(P=0.04)$, but had no influence on SBP or DBP (Table 2). In the placebo group, no changes were observed compared with baseline in MSNA, BRS, SBP, DBP or HR (Table 2).

After simvastatin treatment, MSNA was inversely related to BRS $(r=-0.94, P<0.05)$. In contrast, in the control group and before simvastatin treatment, no correlations were observed between MSNA and BRS (Figure 2).

In both investigated groups, the baseline values of MSNA and BRS were not different among subjects with and without concurrent angiotensin-converting enzyme inhibitor or $\beta$-blocker treatments. 
Table 2 Effects of simvastatin and placebo before and after 8 weeks of treatment

\begin{tabular}{|c|c|c|c|c|c|}
\hline \multirow[b]{2}{*}{ Parameter } & \multicolumn{2}{|c|}{ Simvastatin } & \multicolumn{2}{|c|}{ Placebo } & \multirow{2}{*}{$\begin{array}{c}\text { Interaction group } \times \text { time } \\
\text { P-value }\end{array}$} \\
\hline & Baseline & After therapy & Baseline & After therapy & \\
\hline $\mathrm{DBP}(\mathrm{mm} \mathrm{Hg})$ & $91 \pm 10.8$ & $84 \pm 9.8$ & $86 \pm 11.0$ & $82 \pm 7.5$ & 0.49 \\
\hline HR (beats per min) & $77 \pm 6.7$ & $71 \pm 5.4^{*}$ & $75 \pm 7.7$ & $73 \pm 8.0$ & 0.01 \\
\hline TCHOL $\left(\mathrm{mgdl}^{-1}\right)$ & $249 \pm 30.6$ & $184 \pm 28.3^{* *}$ & $232 \pm 22.1$ & $230 \pm 26.2$ & 0.001 \\
\hline $\mathrm{TG}\left(\mathrm{mgdl} \mathrm{l}^{-1}\right)$ & $156 \pm 52.1$ & $108 \pm 33.2^{*}$ & $159 \pm 52.0$ & $161 \pm 42.3$ & 0.06 \\
\hline MSNA (burst per min) & $36.5 \pm 5.4$ & $27.8 \pm 5.8^{* * *}$ & $33.0 \pm 4.7$ & $32.0 \pm 4.8$ & 0.001 \\
\hline MSNA (burst per 100 heart beats) & $47.8 \pm 8.4$ & $39.4 \pm 8.3^{* * *}$ & $44.5 \pm 7.7$ & $44.0 \pm 7.3$ & 0.001 \\
\hline BRS (ms per mm Hg) & $10.3 \pm 4.1$ & $17.1 \pm 4.3^{* *}$ & $12.7 \pm 6.0$ & $11.0 \pm 6.0$ & 0.04 \\
\hline
\end{tabular}

Abbreviations: ANOVA, analysis of variance; BRS, baroreceptor sensitivity; DBP, diastolic blood pressure; HDL, high-density lipoprotein; HR, heart rate; LDL, low-density lipoprotein; MSNA, muscle sympathetic nerve activity; SBP, systolic blood pressure; TCHOL, total cholesterol; TG, triglycerides.

$P$-values for treatment $\times$ time interaction term (ANOVA); ${ }^{*} P<0.001,{ }^{* *} P<0.01$, ${ }^{* * *} P<0.001$ vs. before treatment.

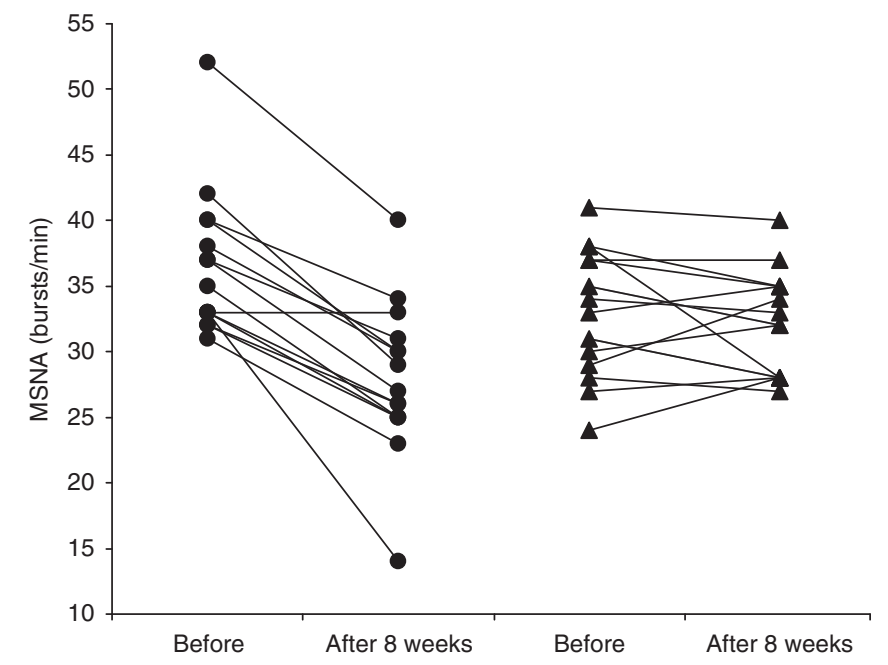

Figure 1 Muscle sympathetic nerve activity (MSNA) (burst per min) results in each participant before and at the end of therapy in $(\bullet)$ simvastatin and (A) placebo groups.

\section{Hormonal indices in simvastatin and placebo groups}

At baseline, plasma levels of catecholamines, NPY, aldosterone, endothelin and renin activity were similar in both groups; none of these parameters changed significantly during treatment (Table 3 ).

\section{DISCUSSION}

This study showed that simvastatin reduced the sympathetic activity measured by microneurography in subjects with hypertension and hypercholesterolemia. Furthermore, we showed that treatment with simvastatin improved the baroreflex control of HR.

\section{Effects of statins on neurohumoral activation}

HMG-CoA reductase inhibitors have become one of the most commonly prescribed medication classes because of current efforts in preventing the progression of atherosclerosis and slowing its clinical sequels. Beneficial effects of statins are typically attributed to their lipid-lowering actions; however, additional cardioprotective effects have also been described, including improvement of endothelial function, upregulation of nitric oxide expression, stimulation of anti-inflammatory and antioxidant effects, and reversal of myocardial remodeling. ${ }^{16-21}$ In addition, several studies in animal and human models found strong interactions between statins and the neurohumoral system, which could be clinically significant. ${ }^{11,22-24}$

Previously, convincing data suggested the involvement of enhanced sympathetic activity in the pathogenesis of cardiovascular diseases, including hypertension and hypertension-related complications. ${ }^{25-27}$ Sympathetic overactivity might be partly explained by peripheral mechanisms, including elevated peripheral chemoreceptor activity, reduced baroreceptor sensitivity and reduced nitric oxide synthesis. ${ }^{28-32}$ Statins can affect baroreceptor sensitivity, ${ }^{33}$ endothelial function $^{17}$ and nitric oxide synthesis; ${ }^{18}$ thus, the speculation arose that statins might modulate sympathetic outflow in cardiovascular disorders. ${ }^{17,18,33}$ Accordingly, our study provided insight into the modulatory role of statins on sympathetic activation in patients with hypertension.

\section{The modulatory role of statins on sympathetic activity}

To date, only a few studies have shown that statins might decrease sympathetic activity in humans. Subjects with a wide spectrum of cardiovascular disorders have been studied. In one study with subjects who had combined hypercholesterolemia, both atorvastatin and fenofibrate partially improved the frequency and time domain indices of HR. ${ }^{34}$ Similarly, in subjects with hypercholesterolemia, with or without coronary artery disease, prolonged atorvastatin therapy improved HRV indices, but showed no correlation between posttreatment LDL concentrations and HRV indices. ${ }^{35}$ In a study of 80 subjects with New York Heart Association class III heart failure, atorvastatin therapy resulted in significant increases in the HRV time domain indices. ${ }^{13}$ In that study, therapy was associated with a reduction of cholesterol; however, the atorvastatin concentration was not correlated with changes in the HRV indices. The findings in this and other studies have suggested that a reduction in sympathetic activity after statin treatment may be associated with mechanisms other than those that lower plasma lipids.

We found no differences in plasma catecholamine concentrations before and after simvastatin therapy. This was consistent with findings on subjects with heart failure treated with statins, who showed no changes in plasma noradrenaline concentrations. ${ }^{36}$ However, another study of subjects with coronary artery disease showed that, compared 

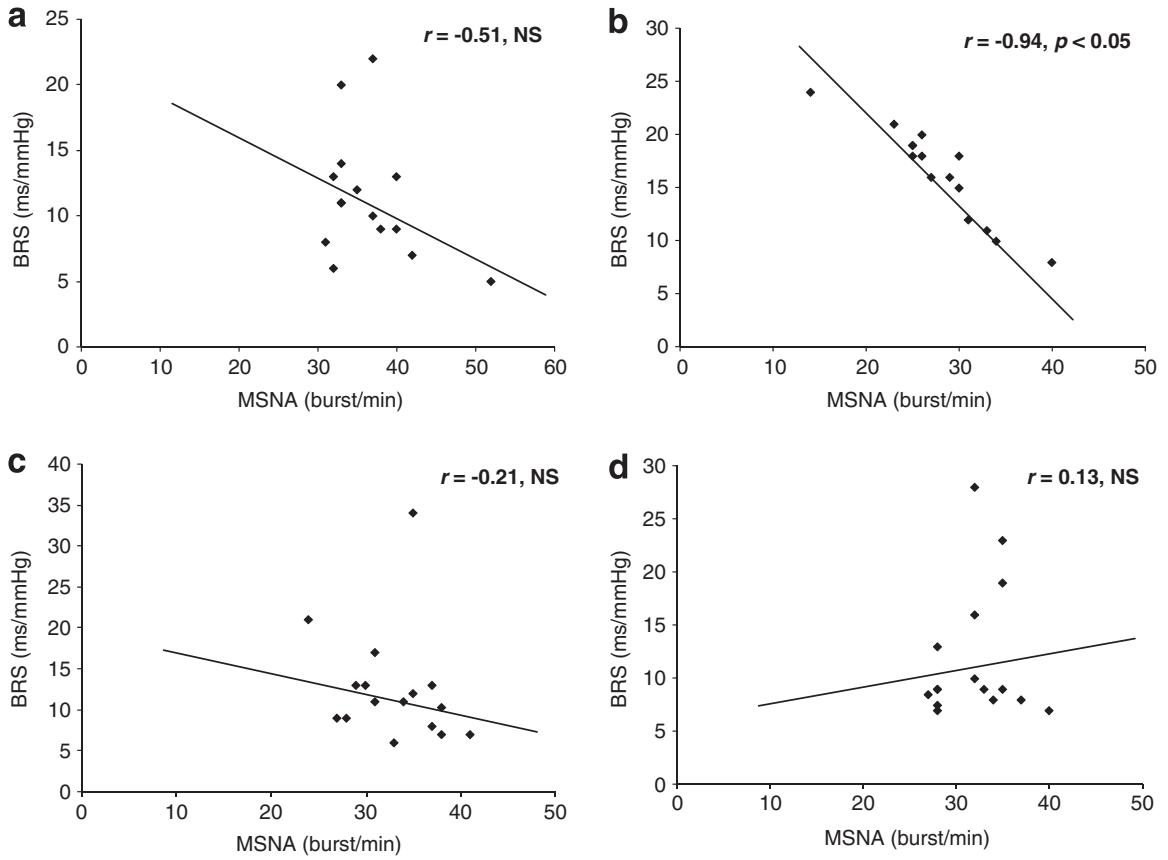

Figure 2 Correlation between baroreceptor sensitivity (BRS) (ms per $\mathrm{mm} \mathrm{Hg}$ ) and muscle sympathetic nerve activity (MSNA) (burst per min) in simvastatin and placebo groups before and after therapy. (a) Simvastatin before therapy, (b) simvastatin after therapy, (c) placebo before therapy and (d) placebo after therapy.

Table 3 Effects of simvastatin and placebo on hormonal indices before and after 8 weeks of treatment

\begin{tabular}{|c|c|c|c|c|c|}
\hline \multirow[b]{2}{*}{ Parameter } & \multicolumn{2}{|c|}{ Simvastatin } & \multicolumn{2}{|c|}{ Placebo } & \multirow{2}{*}{$\begin{array}{c}\text { Interaction group } \times \text { time } \\
\text { P }\end{array}$} \\
\hline & Baseline & After therapy & Baseline & After therapy & \\
\hline Adrenaline $\left(\mathrm{pg} \mathrm{ml}^{-1}\right)$ & $65.0 \pm 44.1$ & $63.0 \pm 41.7$ & $47.2 \pm 24.3$ & $46.7 \pm 30.3$ & 0.48 \\
\hline $\mathrm{NPY}\left(\mathrm{pg} \mathrm{ml}^{-1}\right)$ & $82.5 \pm 17.9$ & $76.9 \pm 11.1$ & $94.0 \pm 14.1$ & $87.8 \pm 19.9$ & 0.90 \\
\hline PRA (ng ml-1 $\mathrm{h}^{-1}$ ) & $2.7 \pm 2.6$ & $2.7 \pm 2.6$ & $1.8 \pm 1.1$ & $1.6 \pm 1.1$ & 0.37 \\
\hline
\end{tabular}

Abbreviations: NPY, neuropeptide Y; PRA, pravastatin.

with placebo, atorvastatin reduced plasma noradrenaline measured at rest in the recumbent position. ${ }^{37}$ The lack of changes in plasma noradrenaline in our study may have resulted from the small number of subjects included, or it may have reflected the fact that circulating noradrenaline represents only a small fraction of the neurotransmitters secreted from nerve terminals. Apart from catecholamines, NPY is a potent neurotransmitter that mediates the sympathoadrenomedullary system. Many studies have shown that NPY is a long-acting vasoconstrictor that directly modulates the effects of other mediators, including noradrenaline, serotonin and angiotensin $\mathrm{II}^{38}$ To date, no studies have investigated the influence of statins on plasma NPY. In our analysis, no changes in hormone concentrations were observed after lipid-lowering therapy; however, again, we may have been limited by the small number of observations.

As the reproducibility and sensitivity of most plasma catecholamine assays are low, we used microneurography recordings to study sympathetic activity. The influence of several different drugs on sympathetic activity has previously been studied with microneurography, but only a few investigations were dedicated to statins. Previously, we showed that a $40 \mathrm{mg}$ dose of atorvastatin reduced sympathetic activity. However, that study was performed without a placebo control. ${ }^{39}$ Another investigation on heart failure subjects showed that MSNA was increased after discontinuing statin therapy and was restored to basal values after resuming therapy. ${ }^{36}$ In this study, the baseline values of sympathetic activity in hypertensive subjects were similar to those reported by other authors. ${ }^{40,41} \mathrm{We}$ showed that 2 months of therapy with simvastatin reduced sympathetic nervous activity.

Mechanisms underlying statin's modulatory effects on sympathetic activity

The mechanisms that underlie the beneficial effects of statins on autonomic function have not been clearly elucidated. However, several mechanisms have been suggested; for example, statin inhibition of atherosclerosis within the aortic arch and carotid arteries might improve the sensitivity of the high pressure baroreceptors. ${ }^{33}$ As a decreased baroreflex contributes to impaired sympathovagal balance, it is possible that an improvement in BRS will lead to an inhibition of sympathetic activity. Indeed, in this study, simvastatin improved the baroreflex control of $\mathrm{HR}$, and this was inversely related to the decrease 
in MSNA. Furthermore, no correlation was found between the MSNA and the baroreflex control of HR in the placebo group or in either group before therapy. Therefore, we hypothesize that the improvement in BRS with simvastatin therapy may have an important role in the subsequent decrease of MSNA in subjects with hypertension and hypercholesterolemia. However, we recognize that the influence of statins on BRS may be highly variable, depending on the time of therapy, type of statin, its lipid-lowering potency and the intensity of atherosclerosis progression in different groups of patients.

Other studies have shown that the mechanisms underlying the sympathoinhibitory effects of statins may involve their inhibitory effects on the renin-angiotensin system and endothelins. In this study, no changes in plasma renin or aldosterone were detected, but endothelin concentrations tended to decrease in the treated group. It was previously established that HMG CoA reductase inhibitors can downregulate angiotensin I and endothelin receptor expression and inhibit the production of angiotensin II and endothelin. ${ }^{42,43}$ The downregulation of angiotensin I receptors in the carotid bodies can reduce tonic chemoreflex activity. ${ }^{44}$ Moreover, both angiotensin II and endothelin are known to stimulate sympathetic nerve traffic in the central nervous system, sympathetic ganglia and sympathetic nerve endings. In this study, some patients were taking drugs that might potentially influence sympathetic outflow, for example, angiotensinconverting enzyme inhibitors and $\beta$-blockers. Only a few studies have investigated this issue, and the results were ambiguous. In one study in patients with chronic heart failure, therapy with the angiotensinconverting enzyme inhibitor benazepril resulted in a reduction in MSNA. ${ }^{45}$ On the other hand, in studies in subjects with hypertension, therapy with the $\beta$-blockers bisoprolol and atenolol did not influence the sympathetic drive measured with MSNA ${ }^{46,47}$ Furthermore, studies with regard to calcium channel blockers showed that chronic therapy did not change MSNA. ${ }^{48}$ In our study, patients had been taking antihypertensive drugs for at least 3 months before the study. Therapy was unchanged during the study period, as reflected by BP and HR values; therefore, the changes we detected in sympathetic drive were attributed to the effects of statins.

In conclusion, this study showed that simvastatin exerted inhibitory effects on sympathetic nervous activity in subjects with hypertension and hypercholesterolemia. The potential mechanism of that action may be related to improvements in BRS; however, other mechanisms may be involved.

\section{PERSPECTIVE}

The practical implications of these data are highly relevant to the management of many cardiovascular disorders. As hypertension and hypercholesterolemia commonly coexist and contribute to the progression of atherosclerosis and increased cardiovascular risk, a pharmacotherapy that targets both disorders is strongly needed. More studies are necessary to corroborate the presented findings and explain the mechanisms underlying the sympathoinhibitory effects of statins.

\section{CONFLICT OF INTEREST}

The authors declare no conflict of interest.

\section{ACKNOWLEDGEMENTS}

Medication was supplied by Gedeon Richter Marketing Polska. Gedeon Richter had no role in the design, conduct or analysis of the present study.

Funding: This study was supported by Polish Ministry of Science Grant KBN 2 P05B01930.
1 Todd PA, Goa KL. Simvastatin. A review of its pharmacological properties and therapeutic potential in hypercholesterolaemia. Drugs 1990; 40: 583-607.

2 Goldstein JI, Brown MS. Regulation of the mevalonate pathway. Nature 1990; 343 : 425-430.

3 Scandinavian Simvastatin Survival Study Group. Randomised trial of cholesterol lowering in 4444 patients with CHD: the Scandinavian Simvastatin Survival Study (4S). Lancet 1994; 344: 1383-1389.

4 Sacks FM, Pfeffer MA, Moye LA, Rouleau JL, Rutherford JD, Cole TG, Brown L, Warnica JW, Arnold JM, Wun CC, Davis BR, Braunwald E. The effect of pravastatin on coronary events after myocardial infarction in patients with average cholesterol levels. N Engl J Med 1996; 335: 1001-1009.

5 The Long-Term Intervention with Pravastatin in Ischaemic Disease (LIPID) Study Group. Prevention of cardiovascular events and death with pravastatin in patients with coronary heart disease and a broad range of initial cholesterol levels. N Engl J Med 1998; 339: 1349-1357.

6 Shepherd J, Cobbe SM, Ford I, Isles CG, Lorimer AR, MacFarlane PW, McKillop JH, Packard CJ. Prevention of coronary heart disease with pravastatin in men with hypercholesterolemia. N Engl J Med 1995; 333: 1301-1307.

7 Downs JR, Clearfield M, Weis S, Whitney E, Shapiro DR, Beere PA, Langendorfer A, Stein EA, Kruyer W, Gotto Jr AM. Primary prevention of acute coronary events with lovastatin in men and women with average cholesterol levels. JAMA 1998; 279: 1615-1622.

8 Heart Protection Study Collaborative Group. MRC/BHF Heart Protection Study of cholesterol lowering with simvastatin in 20536 high-risk individuals: a randomized placebo-controlled trial. Lancet 2002; 360: 7-22.

9 Cannon CP, Braunwald E, McCabe CH, Rader DJ, Rouleau JL, Belder R, Joyal SV, Hill KA, Pfeffer MA, Skene AM. Pravastatin or atorvastatin evaluation and infection therapy - thrombolysis in myocardial infarction 22 investigators. Intensive versus moderate lipid lowering with statins after acute coronary syndromes. $N$ Eng/ J Med 2004; 350: 1495-1504.

10 LaRosa JC, Grundy SM, Waters DD, Shear C, Barter P, Fruchart JC, Gotto AM, Greten H, Kastelein JJ, Shepherd J, Wenger NK. Intensive lipids lowering with atorvastatin in patients with stable coronary disease. N Engl J Med 2005; 352: 1425-1435.

11 Pliquett RU, Cornish KG, Peuler JD, Zucker IH. Simvastatin normalizes autonomic neural control in experimental heart failure. Circulation 2003; 107: 2493-2498.

12 Hamaad A, Sosin M, Lip GY, Macfadyen RJ. Short-term adjuvant atorvastatin improves frequency domain indices of heart rate variability in stable systolic heart failure. Cardiovasc Drugs Ther 2005; 19: 183-187.

13 Vrtovec B, Okrajsek R, Golicnik A, Ferjan M, Starc V, Radovancevic B. Atorvastatin therapy increases heart rate variability, decreases QT variability, and shortens QTC interval duration in patients with advanced chronic heart failure. J Card Fail 2005; 11 : 684-690.

14 Vallbo AB, Hagbarth KE, Torebjork HE, Wallin BG. Somatosensory, proprioceptive, and sympathetic activity in human peripheral nerves. Physiol Rev 1979; 59: 919-957.

15 Watkins LL, Grossman P, Sherwood A. Noninvasive assessment of baroreflex control in borderline hypertension. Hypertension 1996; 28: 238-243.

16 Leeper NJ, Ardehali R, deGoma EM, Heidenreich PA. Statin use in patients with extremely low low-density lipoprotein levels is associated with improved survival. Circulation 2007; 116: 613-618.

17 Marchesi S, Lupattelli G, Siepi D, Schillaci G, Vaudo G, Roscini AR, Sinzinger H, Mannarino E. Short-term atorvastatin treatment improves endothelial function in hypercholesterolemic women. J Cardiovasc Pharmacol 2000; 36: 617-621.

18 Martinez-Gonzalez J, Raposo B, Rodriguez C, Badimon L. 3-Hydroxy-3-methylglutaryl coenzyme $A$ reductase inhibition prevents endothelial NO synthase downregulation by atherogenic levels of native LDLs: balance between transcriptional and posttranscriptional regulation. Arterioscler Thromb Vasc Biol 2001; 21: 804-809.

19 Bellosta S, Via D, Canavesi M, Pfister P, Fumagalli R, Paoletti R, Bernini F. HMG-CoA reductase inhibitors reduce MMP-9 secretion by macrophages. Arterioscler Thromb Vasc Biol 1998; 18: 1671-1678.

20 Aviram M, Rosenblat M, Bisgaier CL, Newton RS. Atorvastatin and gemfibrozil metabolites, but not the parent drugs, are potent antioxidants against lipoprotein oxidation. Atherosclerosis 1998; 138: 271-279.

21 Joukhadar C, Klein N, Prinz M, Schrolnberger C, Vukovich T, Wolzt M, Schmetterer L, Dorner GT. Similar effects of atorvastatin, simvastatin and pravastatin on thrombogenic and inflammatory parameters in patients with hypercholesterolemia. Thromb Haemost 2001; 85: 47-51.

22 Hernandez-Perera O, Perez-Sala O, Navarro-Antolin J, Sánchez-Pascuala R, Hernández G, Díaz C, Lamas S. Effects of the HMG CoA reductase inhibitors atorvastatin and simvastatin on the expression of endothelin-1 and endothelial nitric oxide synthase in vascular endothelial cells. J Clin Invest 1998; 101: 2711-2719.

23 Patel KP, Li YF, Hirooka Y. Role of nitric oxide in central sympathetic outflow. Exp Biol Med 2001; 226: 814-824.

24 Gao L, Wang W, Li YL, Schultz HD, Liu D, Cornish KG, Zucker IH. Simvastatin therapy normalizes sympathetic neural control in experimental heart failure: roles of angiotensin II type 1 receptors and NAD(P)H oxidase. Circulation 2005; 112: 1763-1770.

25 Esler M, Jennings G, Biviano B, Lambert G, Hasking G. Mechanism of elevated plasma noradrenaline in the course of essential hypertension. J Cardiovasc Pharmacol 1986; 8: 39-43.

26 Somers VK, Mark AL, Abboud FM. Potentiation of sympathetic nerve responses to hypoxia in borderline hypertensive subjects. Hypertension 1988; 11: 608-612. 
27 Yamada Y, Miyajima E, Tochikubo O, Matsukawa T, Ishii M. Age related changes in muscle sympathetic nerve activity in essential hypertension. Hypertension 1989; 13: 870-877.

28 Przybylski J. Do arterial chemoreceptors play a role in the pathogenesis of hypertension? Med Hypotheses 1981; 20: 173-177.

29 Trzebski A. Arterial chemoreceptor reflex and hypertension. Hypertension 1992; 19: 562-566.

30 Bristow JD, Honour AJ, Pickering GW, Sleight P, Smyth HS. Diminished baroreflex sensitivity in high blood pressure. Circulation 1969; 39: 48-54.

31 Ribeiro MO, Antunes E, De-Nucci G, Lovisolo SM, Zatz R. Chronic inhibition of nitricoxide synthesis: a new model of arterial hypertension. Hypertension 1992; 20: 298-303.

32 Baylis C, Mitruka B, Deng A. Chronic blockade ofnitricoxide synthesis in the rat produces systemic hypertension and glomerular damage. J Clin Invest 1992; 90: 278-281.

33 Patterson D, Dick JB, Struthers AD. Intensive statin treatment improves baroreflex sensitivity: another cardioprotective mechanism for statins? Heart 2002; 88: 415-416.

34 Melenovsky V, Wichterle D, Simek J, Malik J, Haas T, Ceska R, Malik M. Effect of atorvastatin and fenofibrate on autonomic tone in subjects with combined hyperlipidemia. Am J Cardiol 2003; 92: 337-341.

35 Pehlivanidis AN, Athyros VG, Demitriadis DS, Papageorgiou AA, Bouloukos VJ, Kontopoulos AG. Heart rate variability after long-term treatment with atorvastatin in hypercholesterolaemic patients with or without coronary artery disease. Atherosclerosis 2001; 157: 463-469.

36 Gomes ME, Lenders JW, Bellersen L, Verheugt FW, Smits P, Tack CJ. Sympathoinhibitory effect of statins in chronic heart failure. Clin Auton Res 2009; 20: 73-78.

37 Szramka M, Harriss L, Ninnio D, Windebank E, Brack J, Skiba M, Krum H. The effect of rapid lipid lowering with atorvastatin on autonomic parameters in patients with coronary artery disease. Int J Cardiol 2007; 117: 287-291.
38 Zukowska-Grojec Z, Marks ES, Haass M. Neuropeptide $Y$ is a potent vasoconstrictor and cardiodepressant in rat. Am J Physiol 1987; 253: 1234-1239.

39 Siñski M, Lewandowski J, Ciarka A, Bidiuk J, Abramczyk P, Dobosiewicz A, Gaciong Z. Atorvastatin reduces sympathetic activity and increases baroreceptor reflex sensitivity in patients with hypercholesterolaemia and systemic arterial hypertension. Kardiol Pol 2009; 67: 613-620.

40 Calhoun DA, Mutinga ML, Wyss JM, Oparil S. Muscle sympathetic nervous activity in black and Caucasian hypertensive subjects. J Hypertens 1994; 12: 1291-1296.

41 Grassi G, Cattaneo BM, Seravalle G, Lanfranchi A, Mancia G. Baroreflex control of sympathetic nerve activity in essential and secondary hypertension. Hypertension 1998; 31: 68-72.

42 Wassmann S, Laufs U, Baumer AT, Müller K, Konkol C, Sauer H, Böhm M, Nickenig G. Inhibition of geranylgeranylation reduces angiotensin II-mediated free radical production in vascular smooth muscle cells: involvement of angiotensin AT1 receptor expression and Rac1 GTPase. Mol Pharmacol 2001; 59: 646-654.

43 Mortensen LH. Endothelin and the central and peripheral nervous systems: a decade of endothelin research. Clin Exp Pharmacol Physiol 1999; 26: 980-984.

44 Schultz HD, Li YL. Carotid body function in heart failure. Respir Physiol Neurobiol 2007; 157: 171-185.

45 Grassi G, Cattaneo B, Seravalle G, Lanfranchi A, Pozzi M, Morganti A, Carugo S, Mancia G. Effects of chronic ACE inhibition on sympathetic nerve traffic and baroreflex control of circulation in heart failure. Circulation 1997; 96: 1173-1179.

46 Beloka SP, Gouveia S, Gujic M, Naeije R, Rocha AP, van de Borne P. Differential effects of oral beta blockade on cardiovascular and sympathetic regulation. J Cardiovasc Pharmacol Ther 2009; 4: 323-331.

47 Burns J, Mary DA, Mackintosh AF, Ball SG, Greenwood JP. Arterial pressure lowering effect of chronic atenolol therapy in hypertension and vasoconstrictor sympathetic drive. Hypertension 2004; 4: 454-458.

48 Binggeli C, Corti C, Sudano I, Luscher TH, Noll G. Effects of chronic calcium channel blockade on sympathetic nerve activity in hypertension. Hypertension 2002; 39: 892-896. 